\title{
Aggressiveness of a Neomys fodiens parous female towards conspecific and $N$. anomalus intruders
}

\author{
Natalia L. KRUSHINSKA and Leszek RYCHLIK*
}

\begin{abstract}
Krushinska N. L. and Rychlik L. 1994. Aggressiveness of a Neomys fodiens parous female towards conspecific and $N$. anomalus intruders. Acta theriol. 39: 329-332.

Reactions of a Neomys fodiens (Pennant, 1771) parous female [FP] to 4 conspecific and $3 \mathrm{~N}$. anomalus Cabrera, 1907 intruders were studied quantitatively in enclosure $(135 \times 135 \mathrm{~cm})$ experiments. Total time of observations was $30 \mathrm{hr}$. FP initiated 5.6 intraspecific conflicts per $1 \mathrm{hr}(1.95 / \mathrm{hr}$ of these were pouncings and fightings) with adult males, 0.8 conflicts/hr with a juvenile female, and 4.7 conflicts/hr with a $N$. anomalus adult male. Reactions of $N$. fodiens parous female were several times more aggressive than interactions between non-breeding 'residents' and 'immigrants' of both water shrew species tested under the same conditions in earlier studies.
\end{abstract}

N. K. Koltzov Institute of Developmental Biology, Russian Acad. Sci., 117334 Moscow, Russia (NLK); Mammal Research Institute, Polish Acad. Sci., 17-230 Białowieża, Poland (LR)

Key-words: Neomys fodiens, $N$. anomalus, agonistic and maternal behaviour, territoriality, parous female

\section{Introduction}

The high aggressiveness of breeding females towards intruders, observed in many mammals, is believed as an adaptation against intra- and interspecific infanticide. It was also observed in some Soricidae (e.g. in Blarina brevicauda Platt 1976, Crocidura flavescens - Baxter and Meester 1982, Sorex isodon - Skarén 1982, S. araneus - Churchfield 1990), as well as in Neomys fodiens (Michalak 1983). However, no quantitative data were presented in neither of those studies.

The aim of this preliminary note is to communicate quantitatively about agonistic reactions of a $N$. fodiens parous female to intruders of two water shrew species. In previous studies (Krushinska and Rychlik 1993, Krushinska et al. 1994) it was found that, among non-breeding animals, $N$. fodiens adult males are the most aggressive intraspecificly, and $N$. fodiens females were the most aggressive towards $N$. anomalus newly introduced into the enclosure. Therefore, we also tried to check if $N$. fodiens parous female is (1) more aggressive intraspecificly than adult males and (2) interspecificly than non-breeding females.

\footnotetext{
* to whom reprint requests should be sent
} 


\section{Subject and methods}

Five Neomys fodiens (Pennant, 1771) (3 adult males, 1 ad and 1 juvenile females) and three $N$. anomalus Cabrera, 1907 ( 1 ad and 2 jv males) captured in early summer (June-July) of 1989 in the Białowieża Primeval Forest were used. The $N$. fodiens adult female was captured when pregnant. All animals underwent at least a 2 -week acclimatization in individual cages $(38 \times 30 \times 16 \mathrm{~cm})$. They were then weighed and marked by fur-clipping.

The $N$. fodiens adult female (FP) was placed in the separate enclosure $(135 \times 135 \mathrm{~cm})$ built in a laboratory room located in a basement. The floor was covered with a 5-cm-layer of sand. A small amount of moss for nest-building was put on the sand and changed every 2-3 weeks. The enclosures were also provided with 2 upturned earthenware flower-pots as nest boxes, 2 feeding trays, and 1 water basin $(80 \times 25 \times 15 \mathrm{~cm})$. Meat, milk and water were given ad libitum.

After 11 days FP gave birth to 4 pups. On the 5 th day after parturition $2 \mathrm{~N}$. anomalus juvenile males were introduced into her enclosure, which resulted in an act of infanticide, probably by the mother. On the 6 th day the males were removed. Within the next 46 days, $4 \mathrm{~N}$. fodiens and $1 \mathrm{~N}$. anomalus were successively introduced (each animal for 3 days) to the enclosure. Social behaviour between FP and each of the intruder was observed for $6 \mathrm{hr}$ ( $2 \mathrm{hr}$ per 3 successive evenings). Agonistic behaviour (threatening postures and/or vocalization, pouncing, chasing and fighting) was analysed. Total time of observation was $30 \mathrm{hr}$.

See Krushinska and Rychlik (1993) and Krushinska et al. (1994) for more details about methods of animal keeping, sex and age designation, experimental procedure, behavioural pattern definitions, and data organization.

\section{Results and discussion}

The mean number of conflicts (all kinds of conflicts combined) initiated by the FP parous female with conspecific adult males during $1 \mathrm{hr}$ was 5.6 (Fig. 1). It was several times higher than the number of conflicts between non-breeding $N$. fodiens-'residents' and -'immigrants' observed in the same experimental conditions (Krushinska et al. 1994; Exp. 2), and many times higher than the number of intraspecific conflicts between $N$. fodiens-'immigrants' and members of mixed ( $N$. fodiens $+N$. anomalus) 'resident' groups (Krushinska et al. 1994; Exp. 1). In contrast to it, the $N$. fodiens-'resident' adult female from the mixed group (Krushinska et al. 1994; Exp. 1) did not attacked $N$. fodiens-'immigrant' males at all. Moreover, pouncings and fightings (i.e. the most aggressive conflicts) composed more than third part of all conflicts initiated by FP towards adult males (Fig. 1).

The first $N$. fodiens adult male was introduced to the FP female on the 6th day after parturition, i.e. when she was probably in oestrus. One can believe so because $1 \mathrm{hr}$ after introduction this male entered her nest box and within the next $2 \mathrm{hr}$ they spent a long time together inside without any conflicts. It was also observed that the male climbed the female's back 4 times without irritating her. But as early as on the next day no sexual interactions were noted, and the female again attacked the male and did not let him inside her nest box. The next two $N$. fodiens adult males introduced later were at once subjected to vigorous attacks of FP both in open enclosure and near/in the nest boxes, as well as to persistent chases which become less aggressive on the 3rd day. Neither of the males came into any sexual 
Fig. 1. Aggressiveness (mean number of conflicts initiated by 1 individual during $1 \mathrm{hr}$ ) between the parous female (FP) and intruders in regard to their species, sex and age. Arrows show animals active in conflicts, i.e. $\mathrm{FP} \rightarrow \mathrm{FI}$ means that the parous female attacked conspecific intruder, $\mathrm{AI} \rightarrow \mathrm{FP}$ means that $N$. anomalus intruder attacked the parous female, etc. $n$ - number of 6 -hr observations of a particular type of conflicts.

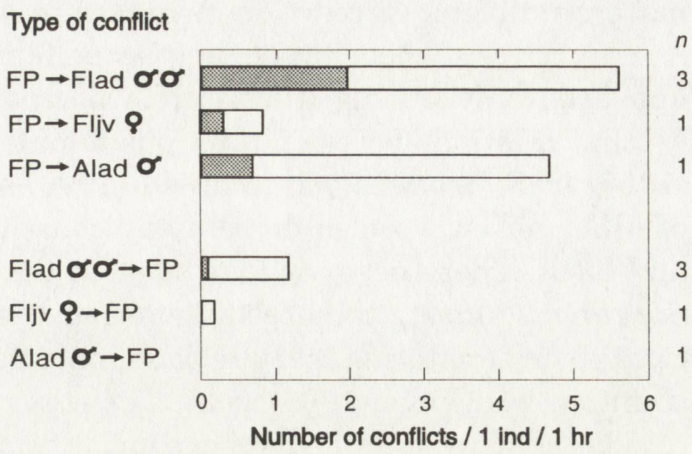

Pouncings and fightings within all conflicts

contact with the female. The reactions of the FP female to the $N$. fodiens young female were comparably milder (Fig. 1).

Thus, the suspension of FP's antagonistic behaviour occurred only during oestrus, after which the female's aggression again intensified, and she defended her nest box against all approaching $N$. fodiens intruders.

Two $N$. anomalus young males, introduced into the enclosure on the 5th day after parturition, were observed entering FP's nest box with the litter. The female chased them away from the nest and made persistant attacks upon them in the enclosure. However, no quantitative data were recorded. The $N$. anomalus adult male, which was introduced to the FP three weeks after parturition, was attacked (mainly frightened away and chased) by the FP female 4.7 times per $1 \mathrm{hr}$ (Fig. 1). For comparison, $N$. anomalus introduced to the mixed groups were attacked as rare as 0.7 times per $1 \mathrm{hr}$ by $N$. fodiens-'residents' (mean for all $N$. fodiens-'residents') and 2.0 times per $1 \mathrm{hr}$ by the $N$. fodiens-'resident' adult female (Krushinska et al. 1994; Exp. 1).

The numbers of conflicts initiated by $N$. fodiens intruders with FP were much lower than opposite, and $N$. anomalus intruder did not initiated any conflict with FP (Fig. 1). Among intruders, only $N$. fodiens adult males initiated some pouncings and fightings with FP, but their number was very low $(0.1 / \mathrm{hr})$.

Thus, the exceptionally high aggressiveness of the $N$. fodiens parous female in regard to intruders of both water shrew species was evident and it was visible even several weeks after parturition. Besides, the level of intraspecific aggressiveness by FP was the highest towards conspecific adult males and the lowest towards young conspecific female. Probably, all adult breeding females can be more aggressive than adult males, which were found to be the most aggressive among non-breeding $N$. fodiens (Krushinska et al. 1994). Similarly, in S. araneus, breeding females seem to dominate adult males as well as juveniles (Moraleva 1989).

A very high degree of aggressiveness of lactating $N$. fodiens females towards adult males was underlined by Michalak (1983). This is undoubtedly a natural 
maternal defensive reaction as according to Michalak (1983), males can eat pups. A temporary suspension of the parous female's agonistic reactions towards males appeared only during the possible postpartum oestrus. An analogous pattern of mutual relations between a parous female and a male was observed by Crowcroft (1957) in $S$. araneus. Churchfield (1990) suggests that also non-oestrous females of other shrew species drive away courting males by vocal threatening, attacks and bites. These observations suggest that in solitary shrews like $N$. fodiens and $S$. araneus, during the breeding period, males and females do not form permanent couples on territories that are commonly defended as it is in e.g. Crocidura russula (Cantoni and Vogel 1989), Suncus etruscus, and S. murinus (Churchfield 1990).

The sharply manifested territoriality of breeding females is a typical feature of many mammals which was observed both in captured Soricidae (e.g. in B. brevicauda - Platt 1976, C. flavescens - Baxter and Meester 1982, S. isodon Skarén 1982), and under natural conditions (e.g. in S. coronatus and $N$. fodiens Cantoni 1993, S. vagrans and $S$. obscurus - Howes 1977). Females of the last-mentioned species actively defend territories over the whole lifetime; within these territories they produce 3-4 litters (Howes 1977). Therefore, the intensified aggressiveness towards immigrants is a natural maternal reaction guaranteeing successful rearing of the offspring by assuring food resources and protection from infanticide and predators.

\section{References}

Baxter R. M. and Meester J. 1982. The captive behaviour of the red musk shrew, Crocidura $f$. flavescens (I. Geoffroy, 1827) (Soricidae : Crocidurinae). Mammalia 46: 11-27.

Cantoni D. 1993. Social and spatial organization of free-ranging shrews, Sorex coronatus and Neomys fodiens (Insectivora, Mammalia). Anim. Behav. 45: 975-995.

Cantoni D. and Vogel P. 1989. Social organization and mating system of free-ranging, greater white-toothed shrews, Crocidura russula. Anim. Behav. 38: 205-214.

Churchfield S. 1990. The natural history of shrews. Christopher Helm Publ., London: xiv + 1-178.

Crowcroft P. 1957. The life of the shrew. Max Reinhardt, London: 1-166.

Hawes M. L. 1977. Home range, territoriality, and ecological separation in sympatric shrews, Sorex vagrans and Sorex obscurus. J. Mammal. 58: 354-367.

Krushinska N. L. and Rychlik L. 1993. Intra- and interspecific antagonistic behaviour in two sympatric species of water shrews: Neomys fodiens and N. anomalus. J. Ethol. 11: 11-21.

Krushinska N. L., Rychlik L. and Pucek Z. 1994. Agonistic interactions between resident and immigrant sympatric water shrews: Neomys fodiens and N. anomalus. Acta theriol. 39: 227-247.

Michalak I. 1983. Reproduction, maternal and social behaviour of the European water shrew under laboratory conditions. Acta theriol. 28: 3-24.

Moraleva N. V. 1989. Intraspecific interactions in the common shrew Sorex araneus in Central Siberia. Ann. zool. Fenn. 26: 425-432.

Platt W. J. 1976. The social organisation and territoriality of short-tailed shrew (Blarina brevicauda) populations in old-field habitats. Anim. Behav. 24: 305-318.

Skarén U. 1982. Intraspecific aggression and postnatal development in the shrew Sorex isodon Turov. Ann. zool. Fenn. 19: 87-91. 